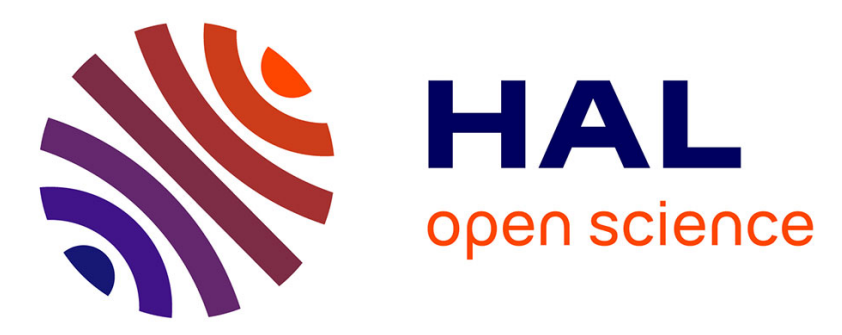

\title{
Comparative AFM nanoscratching tests in air of bulk copper and electrogenerated cuprous oxide films
}

Lila Chaal, Catherine Debiemme-Chouvy, Claude Deslouis, Georges Maurin, Alain Pailleret, Boualem Saidani

\section{- To cite this version:}

Lila Chaal, Catherine Debiemme-Chouvy, Claude Deslouis, Georges Maurin, Alain Pailleret, et al.. Comparative AFM nanoscratching tests in air of bulk copper and electrogenerated cuprous oxide films. Surface Science: A Journal Devoted to the Physics and Chemistry of Interfaces, 2011, 605 (1-2), pp.121-130. 10.1016/j.susc.2010.10.009 . hal-00808467

\section{HAL Id: hal-00808467 https://hal.sorbonne-universite.fr/hal-00808467}

Submitted on 24 Apr 2015

HAL is a multi-disciplinary open access archive for the deposit and dissemination of scientific research documents, whether they are published or not. The documents may come from teaching and research institutions in France or abroad, or from public or private research centers.
L'archive ouverte pluridisciplinaire HAL, est destinée au dépôt et à la diffusion de documents scientifiques de niveau recherche, publiés ou non, émanant des établissements d'enseignement et de recherche français ou étrangers, des laboratoires publics ou privés. 


\section{Comparative AFM nanoscratching tests in air of bulk copper and electrogenerated cuprous oxide films}

Lila Chaal, ${ }^{a, b, c}$, Catherine Debiemme-Chouvy ${ }^{b, c}$, Claude Deslouis $^{b, c}$, Georges Maurin $^{b, c}$, Alain Pailleret ${ }^{b, c^{*}}$, Boualem Saidani $^{a}$

${ }^{a}$ Laboratoire de Technologie des Matériaux et de Génie des Procédés, Equipe Electrochimie et Corrosion, Faculté de la Technologie, Université A. Mira - Béjaia (06000), Algeria

${ }^{\mathrm{b}}$ CNRS, UPR 15, Laboratoire Interfaces et Systèmes Electrochimiques, (LISE, case courrier 133), 4 Place Jussieu, F-75005, Paris, France

${ }^{c}$ UPMC Univ Paris 06, UPR 15, Laboratoire Interfaces et Systèmes Electrochimiques, (LISE, case courrier 133), 4 Place Jussieu, F-75005, Paris, France

*Corresponding author phone: + 33144274169 . Fax: + 33144274074 .

E-mail: alain.pailleret@upmc.fr

\section{ABSTRACT}

The normal and lateral spring constants of rectangular silicon AFM cantilevers bearing pyramidal silicon tips were accurately calibrated using a procedure that takes into account their tilt compared to horizontal orientation and their trapezoidal cross-section. Such systems were used to carry out nanoscratching tests in air on technical substrates presenting a moderate roughness $(\mathrm{RMS} \approx 40 \mathrm{~nm}$ ) and made either from bulk copper or from cuprous oxide thin films electrogenerated on copper. The various events occurring during these nanoscratching procedures were characterized in details. In particular, the features of the scars appearing on the scratched zones and SEM observations of the AFM tips used during the nanoscratching procedures are described and exploited to establish a better understanding of the effects of the nanoscratching procedures on the targeted samples. In the case of 
electrodeposited $\mathrm{Cu}_{2} \mathrm{O}$ films, these effects are discussed with the help of chemical and structural characterizations using XPS and XRD studies. All this set of information is used i) to describe the history of the nanoscratching tests and ii) to compare mechanical resistance of bulk copper and electrogenerated $\mathrm{Cu}_{2} \mathrm{O}$ thin films to nanoscratching tests carried out in air. The wear mechanism occurring during nanoscratching tests is discussed for both kinds of samples and compared with the one observed during erosion in erosion-corrosion tests.

\section{KEYWORDS}

nanoscratching test, atomic force microscopy (AFM), x-ray photoelectron spectroscopy (XPS), cuprous oxide, copper, erosion-corrosion

\section{MANUSCRIPT TEXT}

\section{Introduction}

Erosion-corrosion phenomena are particular cases of corrosion. They result mainly from a fluid circulating at a fast flowing rate along a metallic surface. They are potentially influenced by geometrical characteristics of metallic installations. Erosion-corrosion phenomena are increasingly investigated nowadays as they potentially have a severe impact on the integrity of fluid networks in industry and pollution in environment. As an illustration, one can cite among the various installations or metallic parts exposed to such corrosion process, distribution networks of either cold or hot water, metallic structures in ports, pipelines, thermal exchangers, pumps, turbines or propellers for example. In fact, soft metals (copper and lead for example) as well as metals whose resistance to corrosion strongly depends on the stability of a superficial film (aluminum, stainless steels, other steels) are all expected, and were actually shown, to be indeed victims of erosion-corrosion phenomena. In the latter cases, turbulent flows may lead to a systematic and progressive destruction of the protective films (such as oxide films for example), which obviously results in very high 
corrosion rates for the bare metals. Such situation was indeed found to occur for stainless steels in artificial chlorinated media [1], carbon steels in seawater [2] as well as copper and copper alloys [3-5]. In a previous experimental investigation related to erosion-corrosion phenomena, cuprous oxide $\left(\mathrm{Cu}_{2} \mathrm{O}\right)$ was chosen as an experimental model of moderately adherent protective coating of copper. It was exposed to erosion-corrosion risks produced by corrosive aqueous solutions under measurable and controlled flow conditions using a socalled rotating cage setup [6]. This choice was made on purpose so as to characterize the beneficial effect of hydrodynamic drag reducing agents, such as cationic surfactants, in erosion-corrosion situations.

Cuprous oxide is the most frequently encountered corrosion product of copper [7]. Its formation is known to depend on solution $\mathrm{pH}$, potential of copper and composition of the electrolytic solution. For example, chloride traces deeply complicate and accelerate copper corrosion at the copper/aqueous solution interface. Cuprous oxide is also a well-known p-type semiconductor that presents moreover interesting optical and magnetic properties [8]. Lately, cuprous oxide received considerable attention due to its potential applications in solar energy conversion, nanoelectronics, magnetic storage devices, catalysis, biosensing and lithium ion batteries [8].

Our long term objective is to correlate characteristic mechanical parameters of electrogenerated cuprous oxide films and bulk copper with the mechanical resistance they present during erosion-corrosion experiments carried out in our research group. During these latter experiments, critical shear stresses exerted by the moving fluids led to the partial removal of the cuprous oxide films electrodeposited on bulk copper.

In the frame of this contribution, our purpose was i) to show the feasibility of AFM nanoscratching tests on rather rough electrogenerated cuprous oxide films and bulk copper samples $(\mathrm{RMS} \approx 40 \mathrm{~nm}$ ), ii) to identify the various events occurring during these tests, iii) to 
establish from these tests strategies leading to characteristic mechanical parameters of the targeted materials as well as to a better understanding of the observed wear mechanisms.

\section{Experimental Methods}

Bulk copper samples were prepared from copper rods (diameter: 5 or $10 \mathrm{~mm}$ ) purchased from Goodfellow (Purity $99.99 \%$ ), which were coated with an insulating cataphoretic lacquer and subsequently embedded in an epoxy resin. The cross section of these copper rods was first polished on emery SiC paper up to 1200 grade, then on a microabrasive paper made from alumina deposited on polyester film (grain size $9 \mu \mathrm{m}$ (MOA 9), ESCIL, Chassieu, France). The resulting copper electrodes were rinsed with demineralized water, then placed in an ultrasonic bath for 10 minutes, rinsed again, dried, and finally stored in a dessicator until testing. They were then used as samples for nano-scratching experiments of bulk copper or as working electrodes for the electrogeneration of cuprous oxide thin films. In this latter case, the retained electrochemical procedure implied a usual three electrode electrochemical cell including a platinum counter electrode and a mercury/mercurous sulfate saturated reference electrode (SSE). The three electrodes were connected to a SOTELEM potentiostat/galvanostat and used for the electrodeposition as well as for the electrochemical characterization of the resulting $\mathrm{Cu}_{2} \mathrm{O}$ films.

$\mathrm{Cu}_{2} \mathrm{O}$ films were electrogenerated by oxidizing anodically rotating copper disks in the galvanostatic mode in a corrosive aqueous solution containing $\mathrm{Na}_{2} \mathrm{SO}_{4}(0.1 \mathrm{M})$ and $\mathrm{NaCl}(1$ $\mathrm{mM})$ at $\mathrm{pH}$ 8. In this purpose, the copper electrode was polarized for one hour at a current density of $1 \mathrm{~mA} / \mathrm{cm}^{2}$ while its rotation speed was kept constant at $100 \mathrm{rpm}$. These experimental conditions were close to those used in an earlier work dealing with the behaviour of copper covered with a copper oxide layer in neutral media in erosion-corrosion experiments [9]. Moreover, $\mathrm{pH}$ was raised to slightly alkaline values so as to promote 
efficiently the formation of cuprous oxide layers according to Pourbaix' diagram of copper. Little $\mathrm{NaCl}$ amounts were also added to the electrolytic solution in order to prevent cuprous oxide films from self-healing once they were partly pulled out during the erosion-corrosion experiments [6]. The presence of sodium chloride was thought to provoke a few morphological, and possibly mechanical, heterogeneities that were necessary to allow the resulting cuprous oxide films to offer a moderate mechanical resistance to the erosioncorrosion tests.

In a second step, these electrogenerated $\mathrm{Cu}_{2} \mathrm{O}$ films were thoroughly characterized using ex-situ techniques such as X-Ray Diffraction (XRD), and X-Ray Photoelectron Spectroscopy (XPS) as well as voltammetry.

XRD analyses were carried out using a horizontal goniometer (Philips) and a filtered $\mathrm{MoK}_{\alpha}$ source. The resulting diffractograms were interpreted by comparing them with JCPDS files.

XPS analyses were carried out at ITODYS laboratory (Paris, France) using a VG ESCALAB 250-iXL spectrometer. The X-ray source was monochromatic Al $\mathrm{K}_{\alpha}$ radiation $(1486,6 \mathrm{eV})$. Before analysis, the surface of the samples was etched with $\mathrm{Ar}^{+}$cations in order to remove the native oxide and/or the contamination layer $(\approx 1 \mathrm{~nm})$. The high-resolution spectra were recorded with a pass energy of $20 \mathrm{eV}$ in the constant analyzer energy mode. The detection angle was $90^{\circ}$ with respect to the sample plane. The photoelectron peaks were analysed after subtraction of the background calculated using Shirley's method.

AFM scratching and imaging experiments were carried out on copper working electrodes either freshly polished or coated with electrogenerated cuprous oxide thin films. For this purpose, these substrates were immobilized below the AFM tip of the Molecular Imaging AFM setup using a home made sample holder. This setup was composed of a PicoLE base equipped with a micro-positioning device allowing the precise positioning of the 
AFM tip in the $\mathrm{x}-\mathrm{y}$ plane of the sample, a large zone AFM scanner $(100 \mu \mathrm{m} \times 100 \mu \mathrm{m})$ bearing a photo-detector and the AFM nose adequate for tapping mode AFM (TM-AFM) experiments. A PicoScan 2100 controller connected to a computer was used to drive the scanner and to collect the data generated by the laser impact on the photo-detector. In this purpose, rectangular silicon cantilevers bearing pyramidal silicon tips were used. The resonance frequency and spring constant announced by the AFM tip provider were in the ranges $260-365 \mathrm{kHz}$ and $25-50 \mathrm{~N} . \mathrm{m}^{-1}$ respectively. Nanoscratching and subsequent imaging experiments were carried out ex-situ in air using the contact and TM-AFM modes respectively. All AFM images shown hereafter underwent a tilt correction process.

The scanning electron microscopy (SEM) images were obtained with the help of an Ultra55 Zeiss field-emission gun-SEM (FEG-SEM) microscope.

\section{Results}

Theoretical considerations and experimental calibration of the tip/cantilever system

An accurate calibration of the cantilever/tip systems is crucial if one wants to extract quantitative and comparable information from force measurements or nanoscratching experiments carried out using an AFM equipment. The calibration procedure reported hereafter is easily applicable to most rectangular cantilevers as it does not necessitate any substrates or cantilever/tip systems elaborated especially for calibration purposes. As only rectangular cantilevers were used throughout this work, the force calibration was relatively simple. On its own, a cantilever immobilized at one end and bearing a pyramidal tip at the opposite end displays a mechanical behaviour that requires eight spring constants to be described accurately [10]. Although an analytical expression has been proposed for each of them in literature, only two of them, namely the normal spring constant, $\mathrm{k}_{\mathrm{N}}$, and the lateral spring constant, $\mathrm{k}_{\mathrm{L}}$, are systematically exploited for the quantitative determination of 
mechanical properties of materials using AFM [11]. They express the ability of the cantilever for simple normal bending and lateral friction (or torsion) respectively. These two major constants can be calculated for a cantilever beam with a rectangular cross section from the following expressions, respectively [10,11]:

$$
k_{N}=\frac{3 E_{S i} I}{L^{3}}
$$

And

$$
k_{L}=\frac{4 G_{S i} I}{L h^{2}}
$$

$I$ is the moment of inertia of the cantilever beam. In the case of a rectangular cross section, $I$ can be calculated using the following expression:

$$
I=\frac{w t^{3}}{12}
$$

In these expressions, $E_{S i}$ is Young's modulus of the cantilever $\left(1.69 \times 10^{11} \mathrm{~N} / \mathrm{m}^{2}\right.$ or 169 GPa for silicon [11]), $\mathrm{G}_{\mathrm{Si}}$, its shear modulus $\left(0.5 \times 10^{11} \mathrm{~N} / \mathrm{m}^{2}\right.$ or $50 \mathrm{GPa}$ for silicon [11]), w, its width, $\mathrm{L}$, its length, $\mathrm{t}$, its thickness while $\mathrm{h}$ is the height of the tip. These four latter geometrical parameters can be accurately measured using FEG-SEM images of the cantilever/tip systems. Moreover, it has been argued in literature that a non-rectangular cross section makes expression (3) invalid for the calculation of the moment of inertia [12]. As it was observed from FEG-SEM observations that the cantilevers used in this work actually have a trapezoidal cross section, a more adequate expression of $I$, the moment of inertia, was used instead of (3), according to literature [12]:

$$
I=\frac{t^{3}\left(a^{2}+4 a b+b^{2}\right)}{36(a+b)}
$$

Here, $a$ and $b$ are respectively the width of top and bottom surfaces of the cantilever. Another parameter influencing substantially the value of the normal spring constant is the tilt angle of the cantilever by comparison with horizontal once it is placed in its work position, as recently noticed in literature [13]. Heim et al. indeed showed that this spring constant is 
actually divided by a factor $\cos ^{2} \alpha(1-(2 \mathrm{~h} \tan \alpha) / \mathrm{L})^{-1}$. In this correction factor, $\alpha$ is the tilt angle of the cantilever by comparison to the horizontal direction. In our experimental conditions, cantilevers were found to be tilted by an angle of 7 degrees once they are placed on the nose of the AFM scanner.

By taking into account each of the adjustments reported above in the expression of $\mathrm{k}_{\mathrm{N}}$ (1), one obtains the following expression.

$$
k_{N}=\frac{E_{S i} t^{3}\left(a^{2}+4 a b+b^{2}\right)}{12 L^{3}(a+b) \cos ^{2} \alpha\left(1-\frac{2 h}{L} \tan \alpha\right)}
$$

Once $\mathrm{k}_{\mathrm{N}}$ is experimentally determined, $\mathrm{k}_{\mathrm{L}}$ can easily be deduced using a well established relation linking them [14]. Alternatively, one can use equation (2) in which the moment of inertia will be replaced by the expression given in (4).

$$
k_{L}=\frac{G_{S i} t^{3}\left(a^{2}+4 a b+b^{2}\right)}{9(a+b) L h^{2}}
$$

If one wants to determine the normal and lateral forces applied or undergone respectively by the cantilever/tip system, other important parameters that need to be precisely determined are the angular sensitivities, $S_{N}$ and $S_{L}$ expressed in $n m / V$, of the four quadrants photodetector, with respect to change in the angles for vertical and torsional deformation of the cantilever. The determination of $\mathrm{S}_{\mathrm{N}}$ can be achieved by exploiting force vs. distance curves obtained on incompressible surfaces such as glass or alumina for example, where elastic deformations of the substrate are negligible $[10,11]$. In such cases, the vertical movement of the scanner equals the deflection of the cantilever. The relation between the difference of the vertical signals on the four-quadrant detector, $\mathrm{V}_{\mathrm{N}}$, and the distance from the surface, $z$, is therefore deduced from the slope of the elastic part of the resulting curve. In our experimental conditions, $\mathrm{S}_{\mathrm{N}}$ was found to be $10 \mathrm{~nm} / \mathrm{V}$ from force distance curves obtained on glass (Fig. not shown). As the four quadrants of the photodetector are located symmetrically 
in the same plane perpendicularly to the laser beam, one can consider in a first approximation that $\mathrm{S}_{\mathrm{N}}$ and $\mathrm{S}_{\mathrm{L}}$ take identical values.

Once $\mathrm{k}_{\mathrm{N}}, \mathrm{k}_{\mathrm{L}}$, and $\mathrm{S}_{\mathrm{N}}$ are determined experimentally, it is then possible to calculate accurately the normal and lateral forces, namely $F_{N}$ and $F_{L}$ respectively. The former is calculated as a function of $\mathrm{V}_{\mathrm{N}}$, the voltage measuring the deflection of the cantilever while the latter involves $\mathrm{V}_{\mathrm{L}}$, the voltage expressing the friction of the cantilever that is read during the nanoscratching experiments, using the following expressions [11]:

$$
\begin{gathered}
F_{N}=k_{N} S_{N} V_{N} \\
F_{L}=\frac{3}{2} k_{L} \frac{h}{L} S_{L} V_{L}
\end{gathered}
$$

The procedure detailed above was applied for each of the AFM tips used in this contribution in order to determine accurately the normal force used for each of the nanoscratching tests reported hereafter (see Table 1).

\section{Nanoscratching tests of bulk copper}

Fig. 1a shows an AFM topography image obtained in tapping mode of a portion of a disk electrode made of bulk copper. It includes two zones that each underwent a nanoscratching test (see zones $\mathrm{A}\left(2 \times 2 \mu \mathrm{m}^{2}\right)$ and $\left.\mathrm{B}\left(2 \times 2 \mu \mathrm{m}^{2}\right)\right)$. The portions of the image shown on Fig. 1a that are situated outside the scratched zones show the copper substrate as it results from the polishing procedure. Deep valleys and high ridges approximately oriented along a diagonal of the image appear to be produced during the removal of copper by the polishing particles. Such features produce a full z-scale of about $115 \mathrm{~nm}$ and a RMS of about $38 \mathrm{~nm}$ on a topography image taken on the same zone before the first nanoscratching test. Zones A and B were both scratched with the help of a unique silicon tip by carrying out five consecutive scans with an applied normal load of $0.729 \mu \mathrm{N}$ and $1.21 \mu \mathrm{N}$ respectively as calculated from Eq. (5) (see Table 1). In both cases, the fast scan direction was orthogonal to 
the axis of the cantilever and the scan rate of the tip was $4 \mu \mathrm{m} \cdot \mathrm{s}^{-1}$. Both zones are clearly delimited by scratching residues, possibly copper and/or silicon dusts produced presumably from the wear of the substrate and/or the tip (this issue will be discussed later on). By comparison with the portions of the image that are outside the scratched zones, it appears clearly that the scratched zones underwent damages whose extent is a consequence of the load applied with the AFM tip during the nanoscratching tests, as no other difference exists between the two corresponding nanoscratching procedures. In zone A, one can notice that copper ridges have been slightly worn (see Fig. 1b) but no square based well was created in the copper substrate in spite of the five consecutive nanoscratching scans. In zone B, copper ridges were almost completely erased, as confirmed from the vertical cross section shown on Fig. 1c as an illustration. Moreover, a weakly deep square based well was dug in the copper substrate (see Figure 1d).

In order to elucidate more deeply the various events occurring during these nanoscratching tests, an SEM image of the AFM silicon tip used is shown on Fig. 2a. This side view of the AFM tip clearly shows that a significant amount of matter was accumulated at the apex of the AFM tip during the nanoscratching tests and conserved there during the subsequent imaging experiments. An EDS analysis of the matter accumulated on the tip due again to electrostatic interactions allowed the identification of copper as the main constituent (see Fig. 2b). As expected, silicon was also identified as it is the initial constitutive material of the AFM tip. Besides these two elements, gold was detected. Indeed, a thin gold film was initially deposited on the whole tip in order to make it sufficiently conductive for SEM imaging. More surprisingly, aluminum was detected, possibly as a consequence of the presence of nanometric polishing residues brought on the copper substrate by alumina based polishing paper. In parallel, one must admit that a thorough comparison of the SEM images obtained before (image not shown) and after use (see Fig. 2a) did not allow observing a 
thorough wear of the silicon tip. This is an important point as it implies that silicon based tips appear to be approximately non-deformable and resistant to wear by comparison to copper during these nanoscratching tests.

A further insight in the scratching tests reported above can be achieved by using the contact radius to line step ratio (CRLS), a parameter introduced recently in literature [15]. Its use requires a theoretical description of the geometry of the tip/sample contact. By considering the substrate as a flat elastic surface in a first approximation and a spherical AFM tip apex, one can use the Hertz model to calculate $\mathrm{R}_{\mathrm{c}}$, the radius of the disk shaped contact zone between the tip and the substrate, which can be approached by [16]:

$$
R_{c}=\left(\frac{3 r F_{N}}{4 E^{*}}\right)^{1 / 3}
$$

In this expression, $\mathrm{r}, \mathrm{F}_{\mathrm{N}}$ and $\mathrm{E}^{*}$ are respectively the radius of curvature of the AFM tip, the applied normal force and the combined elastic modulus which can be calculated from the following equation:

$$
E^{*}=\left(\frac{1-v_{C u}^{2}}{E_{C u}}+\frac{1-v_{S i}^{2}}{E_{S i}}\right)^{-1}
$$

In this equation, $v_{\mathrm{Cu}}$ and $v_{\mathrm{Si}}$ are the Poisson's ratios for copper and silicon respectively whereas $E_{\mathrm{Cu}}$ is Young's modulus for copper. The numerical values used in our calculations for these three parameters are 0.351 [17], 0.278 [18], and $1.3110^{11} \mathrm{~N} / \mathrm{m}^{2}$ [17] respectively. By using the $R_{c}$ value calculated from Eqs. (9) and (10), one can then determine the ideal length of the slow scan axis that is necessary to carry out exclusively load-dependent, and therefore easily exploitable nanoscratching tests, from the following equation [15].

$$
L_{\text {sscan }}^{C R L S}=\operatorname{res}\left(\frac{6 r F_{N}}{E^{*}}\right)^{1 / 3}
$$

In equation (11), res is the resolution (or in other words the number of pixels per line or the number of lines per scan) used during the AFM scan corresponding to the nanoscratching test (res $=512$ in our experimental conditions). By including our experimental conditions in this 
equation, $L_{\text {sscan }}^{C R L S}$ values were found to be $4742 \mathrm{~nm}$ and $5611 \mathrm{~nm}$ respectively for the nanoscratching tests corresponding to zones $A$ and $B$ on Fig. 1a (on condition that $F_{N}$ values were calculated from Equation (5)). From the comparison with $L_{\text {sscan }}$, the length of the slow scan axis actually used for these tests (2000 nm for both tests, see Fig. 1), one can conclude that calculated $L_{\text {sscan }}^{C R L S}$ values were both substantially higher than the $L_{\text {sscan }}$ value used for these two nanoscratching tests. This observation implies that there was a systematic overlap between two consecutive line scans during these nanoscratching tests. This situation generated a large set of additive pressure histories distributed over various locations inside the scratched area of the substrate surface under investigation. The influence of scan overlap in defect generation and wear has already been investigated and identified elsewhere [15]. Interestingly, the nanoscratching tests represented in Fig. 1 and implying different scan overlaps could have been compared more accurately by calculating the map of the real pressure history as a function of location on the nanoscratched areas A and B shown in Fig. 1. Such comparison is beyond the purpose of this work as more nanoscratching tests involving other values for yet more important key-parameters, such as normal force or number of consecutive scans for example, would have been necessary first. At this stage of our experiments, this contribution is rather focused on the feasibility of such nanoscratching tests and the comparison of the behaviours of bulk copper and thin films of electrogenerated cuprous oxide during these tests and not on the effect of scan overlap on these behaviours.

\section{Electrodeposition and characterization of $\mathrm{Cu}_{2} \mathrm{O}$ oxide films on copper}

In a first step, typical $\mathrm{Cu}_{2} \mathrm{O}$ films generated using the experimental electrochemical conditions reported in the experimental part were characterized using linear voltammetry in the cathodic potential range. A typical voltammogram obtained on a copper electrode modified with a cuprous oxide film is shown on Fig. 3 (see continuous line). Unlike the one 
obtained in similar experimental conditions at a freshly polished copper electrode (see dashed line on Fig. 3), it clearly shows a well defined cathodic peak situated at $-1.3 \mathrm{~V}$ vs MSE. In good agreement with literature [19-21], this peak is attributed undoubtedly to the electrochemical reduction of $\mathrm{Cu}_{2} \mathrm{O}$ following the reaction:

$$
\mathrm{Cu}_{2} \mathrm{O}+\mathrm{H}_{2} \mathrm{O}+2 \mathrm{e}^{-} \rightarrow 2 \mathrm{Cu}+2 \mathrm{OH}^{-}
$$

The coulombic charge q measured below this reduction peak can be used to calculate the thickness e of the corresponding cuprous oxide film using Faraday's law:

$$
e=\frac{q M}{z F S \rho}
$$

In this equation, $\mathrm{M}$ is the molar mass of $\mathrm{Cu}_{2} \mathrm{O}\left(143.09\right.$ g.mol$\left.{ }^{-1}\right), \mathrm{z}$, the number of electrons exchanged in the electrochemical reduction reaction $(z=2$ from reaction (12) given above), F, the Faraday constant $\left(F=96490 \mathrm{C} \cdot \mathrm{mol}^{-1}\right), \rho$, the density of cuprous oxide $(\rho=6$ g. $\left.\mathrm{cm}^{-3}\right), \mathrm{S}$, the electrode surface $\left(\mathrm{S}=0.2 \mathrm{~cm}^{2}\right)$. Using these different values, the thickness calculated from Eq. (13) and Fig. 3 is $366 \mathrm{~nm}$. Let us emphasize that this value may provide an underestimation of the real thickness as it does not take into account a likely porosity of these electrogenerated oxide films.

XRD technique allowed the determination of the chemical identity and the crystallographic orientation of the electrogenerated film. A typical diffractogram as well as the interpretation of each of its various peaks are shown in Fig. 4. Let us notice first that the penetration depth of X-rays in our experimental conditions was shown to be largely sufficient to cross the electrogenerated film, indicating thus that the resulting diffractogram mainly contains a contribution of this latter as well as another one from the underlying copper substrate. This latter was cristallographically identified as a bulk copper sample made of (111)- and (200)-oriented crystals in the face centered cubic lattice. XRD analysis also allowed us to conclude that cuprous oxide $\mathrm{Cu}_{2} \mathrm{O}$ (or cuprite) was identified as a main constituent of the whole film, as expected. One can moreover conclude that it displays a 
preponderant (111) orientation in the simple cubic lattice although it must be noticed that a very minor (110) texture was also observed (see peaks corresponding to cuprite in Fig. 4). Besides cuprite, nantokite $(\mathrm{CuCl})$ was also identified undoubtedly with a predominant $(111)$ crystallographic orientation in the face centered cubic lattice (see peaks corresponding to nantokite in Fig. 4). Its presence in the electrogenerated film is often assumed to be due to its low solubility. However, due to the large $\mathrm{Cu}_{2} \mathrm{O}$ intensity, it can be concluded in a first approximation that $\mathrm{CuCl}$ is a minor component.

In order to further confirm the identity of the bulk constituents of the electrodeposited film, XPS technique was also exploited as it expectedly allows differentiating the various oxidation degrees for a given chemical element, namely copper in our case. Literature indeed shows that the presence of copper (II) is justified by a $\mathrm{Cu} 2 \mathrm{p}_{3 / 2}$ peak located at $933.6 \mathrm{eV}$ and accompanied with satellite peaks that appear in the energy range 940-944 eV [22-24a]. On the other hand, $\mathrm{Cu}(\mathrm{I})$ and $\mathrm{Cu}(0)$ species cannot be differentiated as the $2 \mathrm{p}$ electrons have the same binding energy. Such purpose is actually achievable on the basis of the LMM Auger peaks as the shape of these latter differ from $\mathrm{Cu}(0)$ to $\mathrm{Cu}(\mathrm{I})$ [24a]. With the help of these data, XPS spectra obtained either at bare copper electrodes or at copper electrodes coated with a electrogenerated cuprous oxide film were analyzed and compared (see Fig. 5). In the region corresponding to $\mathrm{Cu} 2 \mathrm{p}$, both spectra show two photopeaks appearing at 932.7 and $952.5 \mathrm{eV}$ and corresponding to $\mathrm{Cu} 2 \mathrm{p}_{3 / 2}$ and $\mathrm{Cu} 2 \mathrm{p}_{1 / 2}$ respectively, indicating thus the absence of $\mathrm{Cu}$ (II) (see Fig. 5a). Presence of $\mathrm{Cu}(\mathrm{I})$ was nevertheless confirmed on the basis of the $\mathrm{Cu} \mathrm{LMM}$ spectra corresponding either to metallic copper or to the electrogenerated films (see Fig. 5b). The Auger peak observed for the metallic copper is indeed significantly shifted towards lower kinetic energy (917 eV for $\mathrm{Cu}$ instead of $919 \mathrm{eV}$ for $\mathrm{Cu}_{2} \mathrm{O}$ ). Simultaneously it undergoes a real change in its shape by comparison to the one observed on cuprous oxide coatings. The presence of $\mathrm{Cu}_{2} \mathrm{O}$ was also confirmed with the help of a conclusive interpretation of XPS 
spectrum in the O1s region, as this latter clearly showed a peak at $530.9 \mathrm{eV}$, which is a characteristic of cuprite (spectrum not shown) [24b]. Peaks, such as the Cl2p photopeak, clearly indicate the presence of chloride anions, these latter being obviously bound to copper (I) since no sodium was detected. A quantification attempt provides the following composition: $85 \%$ at. $\mathrm{Cu}_{2} \mathrm{O}$ and $15 \%$ at. $\mathrm{CuCl}$.

Electrochemically generated cuprite based coatings whose chemical composition was thoroughly investigated and reported above were further characterized from a morphological point of view by using AFM in the tapping mode in air (see topography image in Fig. 6 outside the central square zone). This AFM image shows that the cuprous oxide films are mainly continuous although they are not sufficiently thick to hide the valleys and ridges that were produced on copper during the polishing procedure. In other words, the topography existing immediately after polishing on the naked copper disk is maintained after the electrodeposition of a cuprous oxide based coating although this latter creates a granular aspect on the surface.

At this stage, it can be reasonably concluded that the electrochemical procedure that was elaborated in this work indeed allowed the production of a perfectly covering film of cuprous oxide, in good agreement with literature [20,21,25-28], while copper (II) oxide was never observed in the resulting coatings.

\section{Nanoscratching tests of $\mathrm{Cu}_{2} \mathrm{O}$ oxide films}

$\mathrm{Cu}_{2} \mathrm{O}$ thin films were scratched using a procedure close to the one used for the nanoscratching tests carried out on bulk copper. The modified zone was scratched with the help of a silicon tip (see characteristics for tip 2 in Table 1) by carrying out only one nanoscratching scan with an applied normal load of $0.62 \mu \mathrm{N}$ (calculated using Eq. (5), see Table 1). The fast scan direction was orthogonal to the axis of the cantilever and the scan rate 
was $4 \mu \mathrm{m} . \mathrm{s}^{-1}$. On the images shown in Fig. 6 (see topography image on Fig. 6a and amplitude image on Fig. 6b) that were obtained using TM-AFM, one can observe that a portion of the cuprous oxide film was indeed modified as a consequence of the scratching test (see selected framed zone on Fig. 6, 4 x $4 \mu \mathrm{m}^{2}$ ). Unlike zones A and B in Fig. 1, the scratched zone appearing on Fig. 6 is not surrounded by scratching dust. By comparison with the unmodified zone of the film, the unique consequence of the scratching test is thus a disappearance of the granular aspect, as observed mainly from Fig. 6b.

As in the cases of the nanoscratching tests carried out on copper and reported above, the AFM silicon tip used to realize and image this scratching test was observed using SEM (see Fig. 7a). This image does not reveal a significant wear of the AFM tip used to scratch cuprous oxide. As in the case of copper, a significant amount of matter was permanently immobilized at the apex of the AFM tip during the nanoscratching tests. The identification of this matter using EDS led to the conclusion that it is mainly cuprous oxide as copper and oxygen were both detected (see Fig. 7b). Chloride anions were not detected, indicating that the scratched zone was mainly constituted of cuprous oxide. The role and behaviour of this cuprous oxide based overtip were observed to be identical to those of the copper overtip observed on Fig. 2a. Gold was obviously detected again as a gold thin film was initially deposited in order to allow SEM and EDS experiments.

Calculations leading to the contact radius and $L_{\text {sscan }}^{C R L S}$ using Eq. (9-11) respectively were not realised as they both necessitate the knowledge of $E_{\mathrm{Cu}_{2} \mathrm{O}}$ and $v_{\mathrm{Cu}_{2} \mathrm{O}}$, (Young's modulus and Poisson's ratio for cuprous oxide respectively), two characteristics that are unknown for our electrogenerated films of $\mathrm{Cu}_{2} \mathrm{O}$.

By using experimental parameters different from those used for the nanoscratching test illustrated in Fig. 6, one can produce damages much more important than those observed on Fig. 6. The nanoscratching test illustrated on Fig. 8 was carried out on cuprous oxide films 
with the help of a silicon tip (see characteristics for tip 3 in Table 1) by carrying out three consecutive nanoscratching scans with an applied normal load of $0.81 \mu \mathrm{N}$ (calculated using Eq. (5), see Table 1). The fast scan direction was orthogonal to the axis of the cantilever and the scan rate was $4 \mu \mathrm{m} . \mathrm{s}^{-1}$. On the images shown on Fig. 8 (see topography image on Fig. 8a and amplitude image on Fig. 8b) that were obtained using the tapping mode of AFM, one can observe a hole whose depth is approximately $1,1 \mu \mathrm{m}$ as a consequence of the scratching test (see framed zone on Fig. $8,3 \times 3 \mu \mathrm{m}^{2}$ ). This illustration shows that, in spite of i) the moderate hardness of silicon tips and ii) the moderate spring constant of the cantilevers, dramatic damages can be produced in the cuprous oxide film up to a stage allowing the AFM tip to reach the underlying copper substrate. The other conclusion of this illustration is that, by comparison to Fig. 8, the experimental conditions used for Fig. 6 are, as concluded above, very close to the set of parameters allowing the minimum damage of the cuprous films investigated in this work. As expected, it also shows the beneficial effect of the number of scratching scans as the normal forces used for the tests 3 and 4 are not so different.

\section{Discussion}

In the first step of this work dedicated to the calibration of AFM probes used for nanoscratching tests, an equation including additional terms (see Eq. (5)) has been established to calculate the normal spring constant of rectangular cantilevers tilted during their use and presenting a trapezoidal cross section. Advantageously, this calibration procedure based on Eq. (5) relies exclusively on a thorough geometrical characterisation of the AFM tip/cantilever systems using the high resolution of FEG-SEM images. The determination of the lateral spring constant of each of the AFM probes was carried out using Eq. (6). The values are in good agreement with those generally encountered in literature [29].

AFM tips accurately calibrated with the help of the procedure discussed above were then used to carry out nanoscratching tests on rough (or technical) surfaces of bulk copper 
(RMS $\approx 38 \mathrm{~nm}$, full $\mathrm{z}$-scale of about $85 \mathrm{~nm}$ ) with a known applied normal force. Various events occurring during these tests such as local wear of the copper substrate, creation of copper dust immobilized on the substrate and on the AFM tip, as well as a negligible wear of the silicon AFM tip were clearly identified, confirming thus the feasibility of these nanoscratching tests in our experimental conditions. The influence of scan overlap during the nanoscratching, known to lead to additive pressure histories distributed over various locations inside the scratched area of the substrate surface, was already discussed in the results part. A deeper exploration of this important scratching parameter would have required a more specific and larger set of experiments. Nevertheless, it can be concluded from these tests that the nanoscratching test corresponding to zone A in Fig. 1 (five consecutive scans, applied normal load: $0.729 \mu \mathrm{N}$ ) hardly damages bulk copper as it only erases copper ridges initially produced by polishing. Moreover, from the apparent correlation observed between topography and friction data corresponding to the first line of the nanoscratching test carried out in zone A (Figure not shown), it can be deduced that topography influences the friction forces exerted on the AFM tip during nanoscratching tests. This seems to be detrimental to the usual procedure allowing the determination of friction coefficients from nanoscratching tests [30-32]. Although it appears from this latter that the determination of the friction force or friction coefficient may be a way to deduce the hardness of materials on condition that some of their mechanical parameters are known, the feasibility of the determination of the hardness of materials (copper and cuprous oxide in our case) using AFM nanoscratching experiments is somewhat questionable. Let us emphasize that the hardness of materials seems to be an important criteria in erosion-corrosion tests [6]. In another approach offering a quantitative exploitation of nanoscratching tests [33], Colaço et al. suggested a correlation between the volume of matter and the normal force following:

$$
Q=\frac{V}{L}=k_{a b} \frac{F_{N}}{H}
$$


In this equation, $\mathrm{Q}$ is the wear rate, $\mathrm{V}$, the volume of removed material per unit of sliding length (L). Q can also be expressed as a function of $\mathrm{k}_{\mathrm{ab}}$, a constant measuring a probability that the AFM tip behaving as an asperity of a surface produces a mass transfer, i.e produces an abrasive wear, during a nanoscratching procedure. In this case, the two other parameters are $\mathrm{F}_{\mathrm{N}}$, the normal load applied during the nanoscratching test and $\mathrm{H}$, the hardness of the scratched material. By using Eq. 14 in the case of the second nanoscratching test carried out on copper (see zone B on Figure 1) and $\mathrm{H}_{\mathrm{Cu}}=880 \mathrm{MPa}$ [34], one can deduce $\mathrm{k}_{\mathrm{ab}}=$ 4.26 $10^{-3}$ which is a value close to the $0.005-0.05$ range usually mentioned in literature for $\mathrm{k}_{\mathrm{ab}}$ [35]. Let us note that $\mathrm{k}_{\mathrm{ab}}$ is related to a two-body wear situation like those observed in macroscale scratching tests and is therefore a function of the material of the abrasive asperity (or AFM tip in our case). The calculation of $\mathrm{V}$ was carried out from the size of the nanoscratched zone (see Figure 1, zone B) and the estimation of the depth of the wearprint using the difference between the average level of the copper surface and that of the bottom of the wearprint. $\mathrm{L}$ was calculated with the help of the formula $\mathrm{L}=2 \mathrm{Nnl}$ in which $\mathrm{N}$ is the number of consecutive scans carried out during the nanoscratching test, $\mathrm{n}$ is the number of lines per scan in the slow speed direction (512 in our case) and 1 is the length of one scanline.

After a thorough characterisation using voltammetry as well as XRD and XPS spectroscopies, cuprous oxide films electrodeposited on bulk copper electrodes were also submitted to AFM nanoscratching tests. Again, the feasibility was easily shown but the narrow correlations between topography on one side and deflection and friction on the other side are much weaker even though the roughness and z-scale take values close to those measured on the bulk copper samples. By comparison with the granular aspect of the electrodeposited cuprous oxide film [36], the scratched zone resulting from the softest nanoscratching test (one scan, applied normal load: $0.623 \mu \mathrm{N}$, see Fig. 6) appears to be smoothened, indicating a wear threshold situation. The corresponding set of nanoscratching 
parameters is therefore sufficient to produce only a smoothing of the grainy $\mathrm{Cu}_{2} \mathrm{O}$ surface above its average level whereas the more aggressive nanoscratching test carried out on bulk copper (zone A, Fig. 1) was not so efficient. Although the second test (3 consecutive scans, applied normal load: $0.813 \mu \mathrm{N}$, see Fig. 8) carried out on $\mathrm{Cu}_{2} \mathrm{O}$ was only moderately more aggressive than the first one (one scan, applied normal load: $0.623 \mu \mathrm{N}$, see Fig. 6) and, more interestingly, much less aggressive than the second one carried out on bulk copper (5 consecutive scans, applied normal load: $1,21 \mu \mathrm{N}$, see Fig. 1, zone B), it produced a much more spectacular wear scar (see Fig. 8). This set of comparison strongly suggests that bulk copper is mechanically more resistant to these nanoscratching tests than electrogenerated $\mathrm{Cu}_{2} \mathrm{O}$ thin films. The granular structure of our $\mathrm{Cu}_{2} \mathrm{O}$ thin films is likely to play an important role in the wear mechanism observed during these nanoscratching tests.

By using the quantitative exploitation on the nanoscratching test illustrated on Figure 8 and related to $\mathrm{Cu}_{2} \mathrm{O}$ (see Eq. 14), one can deduce that its hardness is $36 \mathrm{MPa}$ if one suggests that $\mathrm{k}_{\mathrm{ab}}$ is 0,05 according to the highest boundary value of $\mathrm{k}_{\mathrm{ab}}$ corresponding to a soft material [35]. This low hardness value seems to be too low to represent the real hardness of cuprous oxide. A higher and therefore more acceptable value of hardness would have resulted from a lower removed volume. As this latter can be easily evaluated with a satisfying accuracy from Figure 8, the value extracted for the hardness of $\mathrm{Cu}_{2} \mathrm{O}$ possibly suggests that the nanoscratching test may not have sollicitated the hardness of the cuprous oxide film but rather another fundamental characteristic of this material such as the adhesion between the constituting grains of the material. Indeed, in the particular case of cuprous oxide, the material structure resulting from the electrodeposition process is presumably heterogeneous due to a grainy structure [36]. In other words, one can suggest that nanoscratching tests actually allow appealing to the adhesion forces existing between the grains, whether they are made of nanometric $\mathrm{Cu}_{2} \mathrm{O}$ or $\mathrm{CuCl}$ (see Figure 4 and 5). It is remarkable that such wear mechanism 
strongly resembles the one observed during erosion in erosion-corrosion tests whose consequences on the integrity of similar cuprous oxide films were reported elsewhere [6]. If such hypothesis was confirmed, adhesion characteristics of the grainy $\mathrm{Cu}_{2} \mathrm{O}$ materials rather than bulk mechanical properties would be necessary to investigate and predict the mechanism and consequences of erosion observed in erosion-corrosion tests from the material view-point. It would then be common to erosion and nanoscratching for cuprous oxide whereas such situation appears strongly unlikely on bulk copper where corrosion may play a more important role than erosion. Further experiments are currently underway to better characterize key structural characteristics of our cuprous oxide films such as porosity or grain structure.

The accurate determination of the normal forces used during the nanoscratching tests reported in this work also provides a conclusive qualitative comparison. Concerning the nanoscratching tests carried out on copper, it appears from the comparison of zones A and B shown on Fig. 1 that the set of experimental conditions beyond which copper can be efficiently scratched in our experimental conditions is actually the one corresponding to zone A $\left(2 \times 2 \mu \mathrm{m}^{2}, 5\right.$ consecutives scans, $F_{N \exp }=1.35 \mu N$ (from Eq. 5 and 7)). In parallel, the nanoscratching test carried out on cuprous oxide and illustrated in Fig. 6 allows the determination of the wear threshold on cuprous oxide films $\left(4 \mathrm{x} 4 \mu \mathrm{m}^{2}, 1\right.$ scan, $F_{N \exp }=0.623 \mu N$ (from Eq. 5 and 7). As a consequence, both experiments can be advantageously compared. At this stage, one can simply deduce that copper is mechanically more resistant towards nanoscratching tests than cuprous oxide, which may again reveal two different wear mechanisms resulting from two different structures, rather than various bulk properties (hardness for example). This result is already quite significant but only qualitative as it is not based on the comparison of the Young's moduli of the two materials involved. 


\section{Conclusion}

In this contribution, nanoscratching tests carried out in air using AFM on technical bulk copper samples (or hand-polished samples, to be differentiated from theoretical (or model) samples such as monocrystals, atomically flat surfaces, ...), either bare or covered with electrogenerated cuprous oxide films are reported. The feasibility of such tests is confirmed with the help of i) the TM-AFM imaging of wear prints and ii) FEG-SEM imaging and EDS analysis of AFM tips. Their quantitative exploitation is delicate as a consequence of the significant roughness of the targeted samples $(\mathrm{z}$-scale $\approx 100-200 \mathrm{~nm})$ and its well known effects on friction coefficient measurements. Nevertheless, a qualitative comparison of these nanoscratching tests was made possible thanks to an accurate determination of the applied normal forces based on an accurate calibration procedure of the cantilever/tip systems employed. It allows concluding that dense bulk copper samples are mechanically more resistant than granular cuprous oxide films electrodeposited on copper towards AFM nanoscratching tests. In a more quantitative exploitation of these tests, a model extracted literature allowed us to deduce an abnormally low value of the hardness for cuprous oxide. This set of information led to suggest two different (surface) wear mechanisms resulting rather from the differences in chemical heterogeneity and structure of bulk copper and electrogenerated cuprous oxide thin films rather than from a given bulk mechanical property (such as hardness). This conclusion is crucial for the development of a better understanding of the degradation of these materials in the course of erosion-corrosion tests.

\section{ACKNOWLEDGMENTS}

S. Borensztajn and F. Pillier are warmly acknowledged for SEM imaging and EDS experiments. LC acknowledges the financial support of the "TASSILI" programs with Algeria ( $\mathrm{N}^{\circ} 03$ MDU 572 and $06 \mathrm{MDU}$ 686). 


\section{REFERENCES}

[1] L. Colombier, J. Hochmann, Aciers inoxydables - Aciers réfractaires, Dunod, Paris, 1965.

[2] J. Tousek, Theoritical aspects of the localized corrosion of metals, Trans. Tech. Publications, 1985, 151.

[3] K.D. Efird, Corrosion 33 (1977) 3-8.

[4] G. Bianchi, G Fiori, P. Longhi, F. Mazza, Corrosion 34 (1978) 396-406.

[5] R.J.K. Wood, S.P. Hutton, D.J. Schiffrin, Corrosion Sci. 30 (1990) 1177-1201.

[6] L. Chaal, C. Deslouis, A. Pailleret, B. Saidani, Electrochim. Acta 52 (2007) 77867795.

[7] H.Y.H.Chan, C.G. Takoudis, M.J. Weaver, J. Phys. Chem. B 103 (1999) 357-365.

[8] a) C.H.B. Ng, W.Y. Fan, J. Phys. Chem. B, 110 (2006) 20801-20807. b) Y.L. Liu, Y.C. Liu, R. Mu, H. Yang, C.L. Shao, J.Y.Zhang, Y.M. Lu, D.Z. Shen, X.W. Fan, Semicond. Sci. Technol. 20 (2005) 44-49. c) T. Mahalingam, J.S.P. Chitra, J.P. Chu, P.J. Sebastian, Materials Letters 58 (2004) 1802-1807. d) A.S. Reddy, G.V. Rao, S. Uthanna, P.S. Reddy, Physica B-condensed matter 370 (2005) 29-34. e) A.S. Reddy, S. Uthanna, P.S. Reddy, Appl. Surf. Sci. 253 (2007) 5287-5292. f) J.Y. Xiang, X.L. Wang, X.H. Xia, L. Zhang, Y. Zhou, S.J. Shi, J.P. Tu, Electrochim. Acta, 55 (2010) 4921-4925.

[9] E.M.M. Sutter, T.T.M. Tran, C. Fiaud, EUROCORR 2004, 12-16 September 2004, Nice, France.

[10] G. S. Watson, B.P. Dinte, J.A. Blach, S. Myhra, J. Phys. D: Appl. Phys. 35 (2002) 2066-2074.

[11] E. Gnecco, R. Bennewitz, O. Pfeiffer, A. Socoliuc, E. Meyer, Chap 11: Friction and Wear on the Atomic Scale, in: B. Bhushan (Ed), Nanotribology and Nanomechanics - An Introduction, Springer, Berlin, 2005, pp557-606. 
[12] M.A. Poggi, A.W. McFarland, J.S. Colton, L.A. Bottomley, Anal. Chem. 77 (2005) 1192-1195.

[13] L.-O. Heim, M. Kappl, H.-J. Butt, Langmuir 20 (2004) 2760-2764.

[14] P. Bilas, L. Romana, B. Kraus, Y. Bercion, J.L. Mansot, Rev. Sci. Instrum. 75 (2004) 415-421.

[15] J.M. Helt, J.D. Batteas., Langmuir 22 (2006) 6130-6141.

[16] H. Hertz, J. Reine Angew. Math. 92 (1881) 156-171.

[17] P.G. Sanders, J.A. Eastman and J.R. Weertman, Acta Mater. 45 (1997) 4019-4025.

[18] P. Hess, Appl. Surf. Sci. 106 (1996) 429-437.

[19] C. Fiaud, Corrosion Sci. 14 (1974) 261-277.

[20] A. Le Gal La Salle-Molin, "Corrosion, passivation et protection du cuivre en solution aqueuse", Ph. D. Thesis, University Paris VI, 1991.

[21] R.M. Souto, S. Gonzalez, R.C. Salvarezza, A.J. Arvia, Electrochim. Acta 39 (1994) 2619-2628.

[22] Handbook of X-Ray photoelectron spectroscopy, Ed. Perkin-Elmer Corporation, USA, 1992.

[23] D. Persson, C. Leygraf, J. Electrochem. Soc. 137 (1990) 3163-3169.

[24] a) D. Briggs, M.P. Seah, Practical surface analysis by Auger and X-ray photoelectron spectroscopy, Wiley, New-York, 1983. b) C. Debiemme-Chouvy, F. Ammeloot, E.M.M. Sutter, Appl. Surf. Sci. 174 (2001) 55-61.

[25] I.I.E Fonseca, A.C.S. Marin, A.C. Sa, Electrochim. Acta, 1992, 37, 2541.

[26] B. Millet, "Etude électrochimique et photoélectrochimique de couches d'oxyde de cuivre semi-conductrices. Rôle d'un inhibiteur de corrosion du cuivre", Ph. D. Thesis, University Paris VI, 1991.

[27] B. Millet, C. Fiaud, C. Hinnen, E.M.M Sutter, Corrosion Sci. 37 (1995) 1903-1918.

[28] E. M. M. Sutter, B. Millet, C. Fiaud, D. Lincot, J. Electroanal. Chem.. 386 (1995) 101109. 
[29] F.J. Giessibl, Y. Sugarawa, S. Morita, H. Hosoi, K. Sueoka, K. Mukasa, A. Sasahara,

H. Onishi, Chap 4: Noncontact Atomic Force Microscopy and Related Topics, in: B. Bhushan

(Ed), Nanotribology and Nanomechanics - An Introduction, Springer, Berlin, 2005, pp 134177.

[30] M. Chiba, M. Seo, J. Electrochem. Soc. 150 (2003) B525-B529.

[31] M. Chiba, M. Seo, Electrochim. Acta 50 (2004) 967-975.

[32] M. Seo, D. Kawamata, J. Phys. D: Appl. Phys. 39 (2006) 3150-3156.

[33] R. Colaço, Wear 267 (2009) 1772-1776.

[34] D. Tabor, Phil. Mag. A 74 (1996) 1207-1212.

[35] I.M. Hutchings, Tribology: Friction and wear of engineering materials, Edward Arnold, London, 1992.

[36] F. Caballero-Briones, A. Palacios-Padrós, O. Calzadilla, F. Sanz, Electrochim. Acta, 55 (2010) 4353-4358. 


\section{LEGENDS}

Table 1: set of experimental parameters related to scratching procedure or cantilever/tip system for each of the four nanoscratching tests commented in this contribution

Fig. 1: a) Topography AFM image obtained using the tapping mode in air of a portion of a copper electrode that includes two zones (A and B) scratched using respectively the sets of parameters $\mathrm{N}^{\circ} 1$ and 2 (see Table 1). b,c,d) vertical profile taken along the corresponding red line drawn on the neighbouring image.

Fig. 2: a) SEM image of the AFM silicon tip used to scratch zones A and B in the contact mode and to produce Fig. 1 in the tapping mode. b) EDS analysis of the matter immobilised on the apex of the tip.

Fig. 3: Linear voltammograms obtained at a copper electrode (dashed line) and at a copper electrode covered with an electrogenerated cuprous oxide film (continuous curve) in an aqueous solution containing $\mathrm{Na}_{2} \mathrm{SO}_{4}(0.1 \mathrm{M})$ and $\mathrm{NaCl}(1 \mathrm{mM})$ at $\mathrm{pH}$ 8. Scan rate: $10 \mathrm{mV} \cdot \mathrm{s}^{-1}$.

Fig. 4: XRD spectrum of a cuprous oxide thin film electrogenerated on $\mathrm{Cu}$.

Fig. 5: a) Cu2p XPS spectrum, b) Cu LMM X-AES spectrum, of copper (dashed line) and an electrogenerated cuprous oxide film (continuous line). An $\mathrm{Ar}^{+}$abrasion was performed before spectrum acquisition.

Fig. 6: a) Topography and b) amplitude AFM images obtained using the tapping mode in air of a portion of a copper electrode covered with an electrogenerated cuprous oxide thin film that include a portion scratched using the set of parameters $\mathrm{N}^{\circ} 3$ (see Table 1).

Fig. 7: a) SEM image of the AFM silicon tip used to scratch a portion of a $\mathrm{Cu}_{2} \mathrm{O}$ film in the contact mode and to produce Fig. 8 in the tapping mode. b) EDS analysis of the matter immobilised on the apex of the tip. 
Fig. 8: a) Topography and b) amplitude AFM images obtained using the tapping mode in air of a portion of a copper electrode covered with an electrogenerated cuprous oxide thin film that include a portion scratched using the set of parameters $\mathrm{N}^{\circ} 4$ (see Table 1). 
Table 1

\begin{tabular}{|c|ccccccc|}
\hline $\begin{array}{c}\text { Nano- } \\
\text { scratching } \\
\text { test } \mathrm{N}^{\circ}\end{array}$ & Figure & Tip & $\begin{array}{c}\mathrm{k}_{\mathrm{N}} \\
\left(\mathrm{N}^{-1}\right)\end{array}$ & $\begin{array}{c}\mathrm{k}_{\mathrm{L}}{ }^{(3)} \\
\left(\mathrm{N} . \mathrm{m}^{-1}\right)\end{array}$ & $\mathrm{S}_{\mathrm{z}}$ & $\begin{array}{c}\mathrm{F}_{\mathrm{N}} \\
(\mu \mathrm{N})\end{array}$ & $\begin{array}{c}\text { Nr of } \\
\text { scans }\end{array}$ \\
\hline 1 & $\begin{array}{c}\text { Fig. } 1(\text { zone A, } \\
\left.2 \times 2 \mu \mathrm{m}^{2}\right)\end{array}$ & 1 & $45.09^{(1)}$ & 1398,80 & 10 & 0.729 & 5 \\
2 & $\begin{array}{c}\text { Fig. } 1(\text { zone B, } \\
\left.2 \times 2 \mu \mathrm{m}^{2}\right)\end{array}$ & 1 & $45.09^{(1)}$ & 1398,80 & 10 & 1.21 & 5 \\
3 & $\begin{array}{c}\text { Fig. } 7 \\
\left(4 \times 4 \mu \mathrm{m}^{2}\right)\end{array}$ & 2 & $61.04^{(1)}$ & 1149,97 & 10 & 0.623 & 1 \\
4 & $\begin{array}{l}\text { Fig. } 10 \\
\left(3 \times 3 \mu \mathrm{m}^{2}\right)\end{array}$ & 3 & $98.95^{(1)}$ & 3100,12 & 10 & 0.813 & 3 \\
\hline
\end{tabular}

Each of the AFM tips characterised in this table were imaged using FEG-SEM in order to provide plan view and side view images necessary to measure the cantilever and tip dimensions. Spring constants were calculated with ${ }^{(1)}$ Eq. 5, ${ }^{(2)}$ Eq. $6,{ }^{(3)}$ Eq. 7. 


\section{FIGURES}
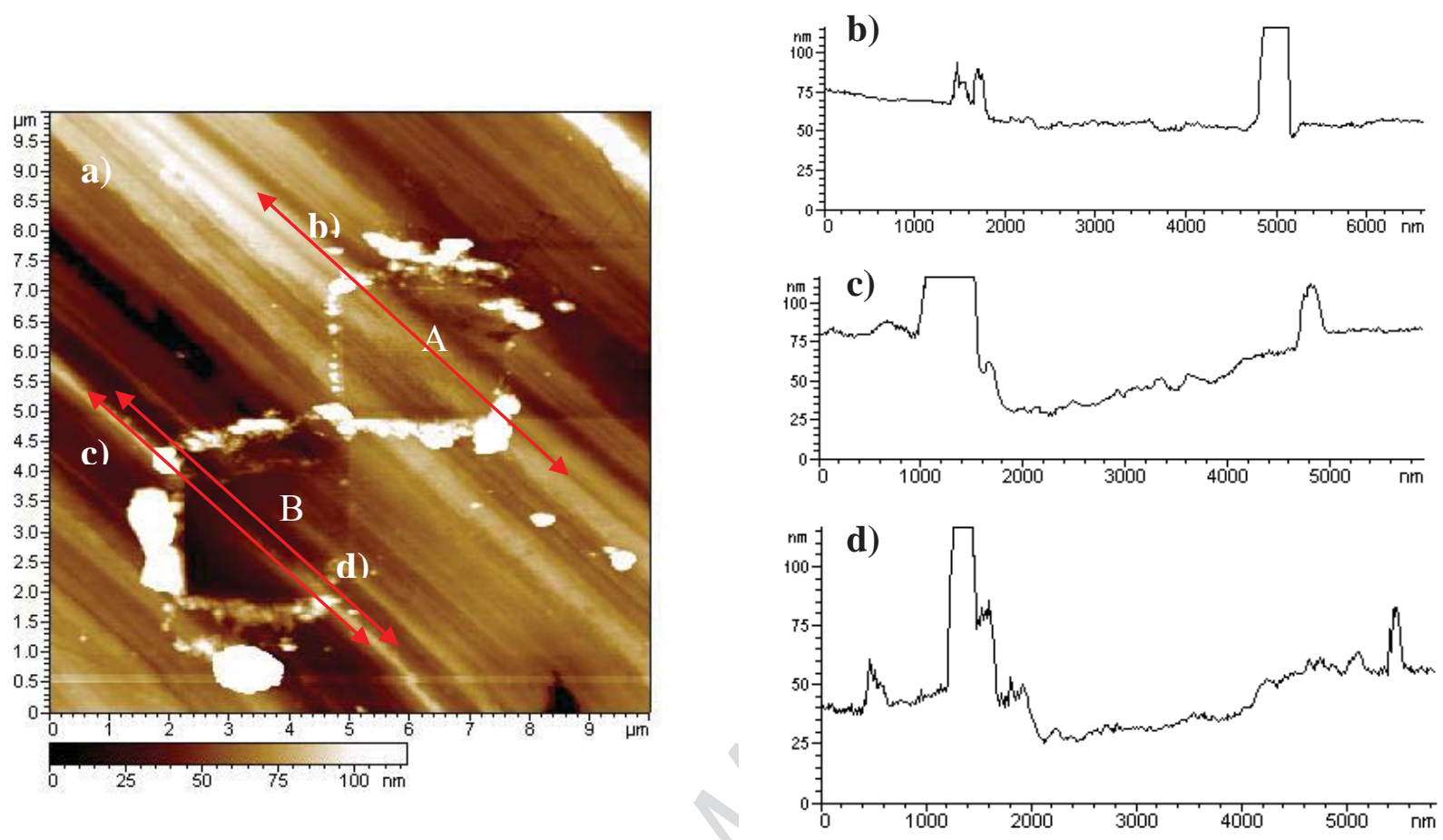

Fig. 1 


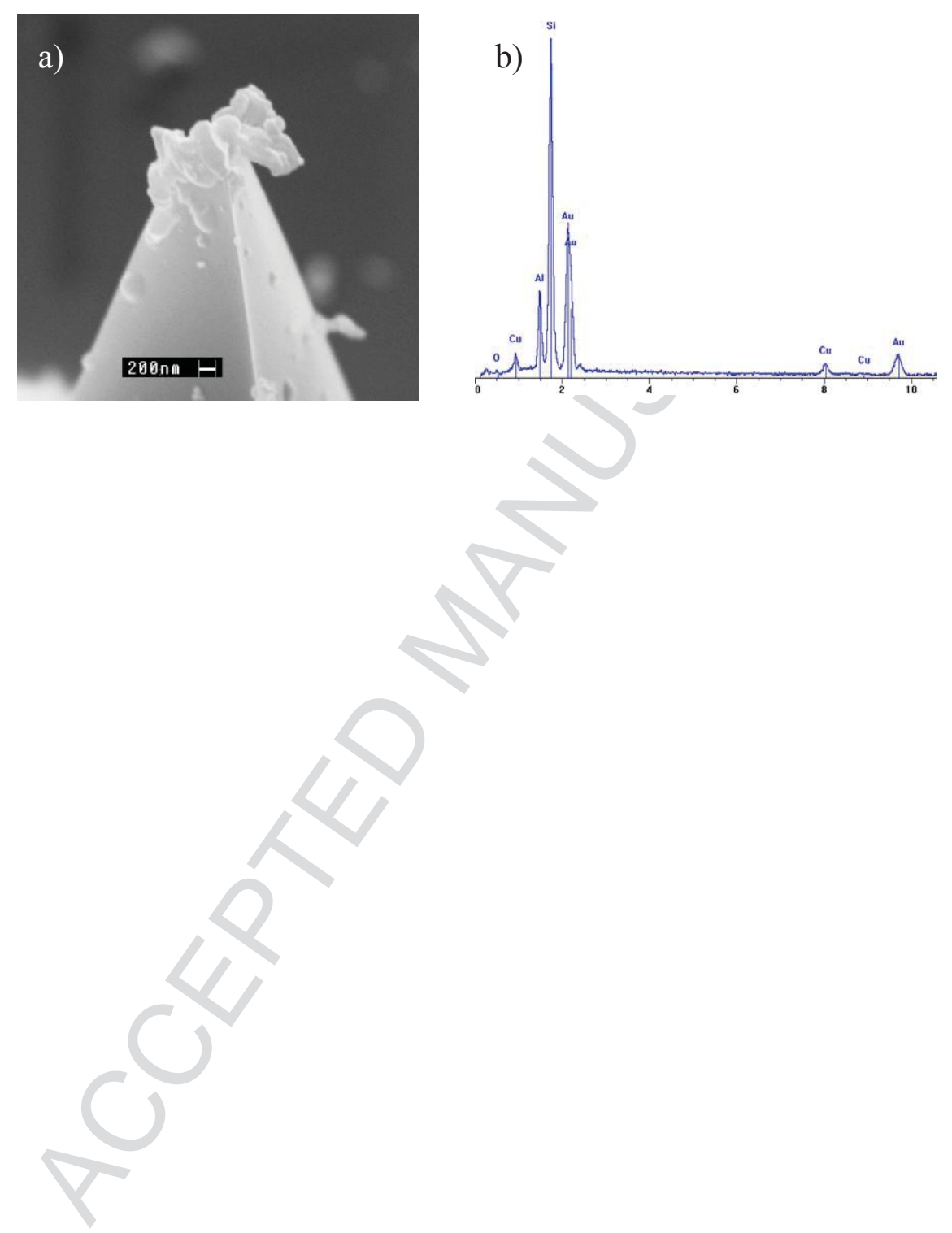

Fig. 2 


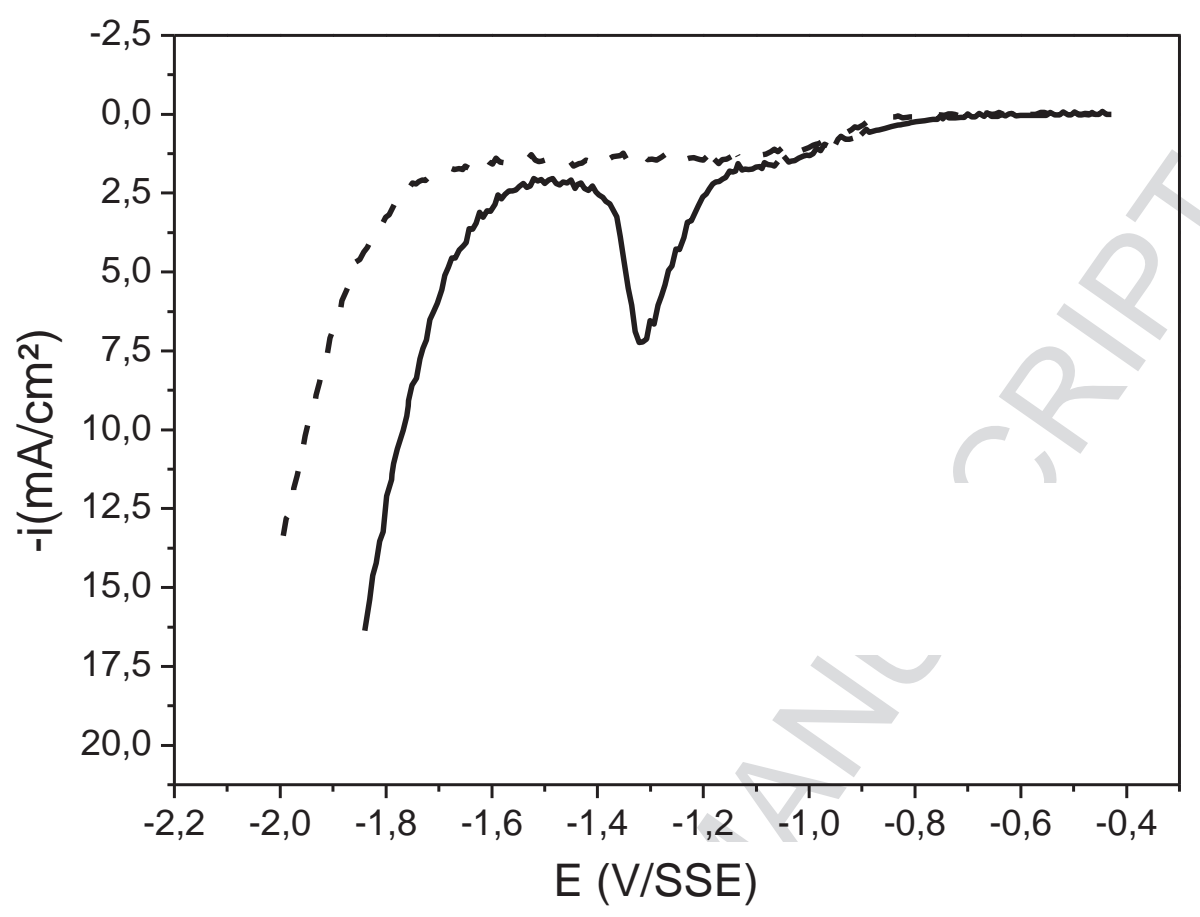

Fig. 3 


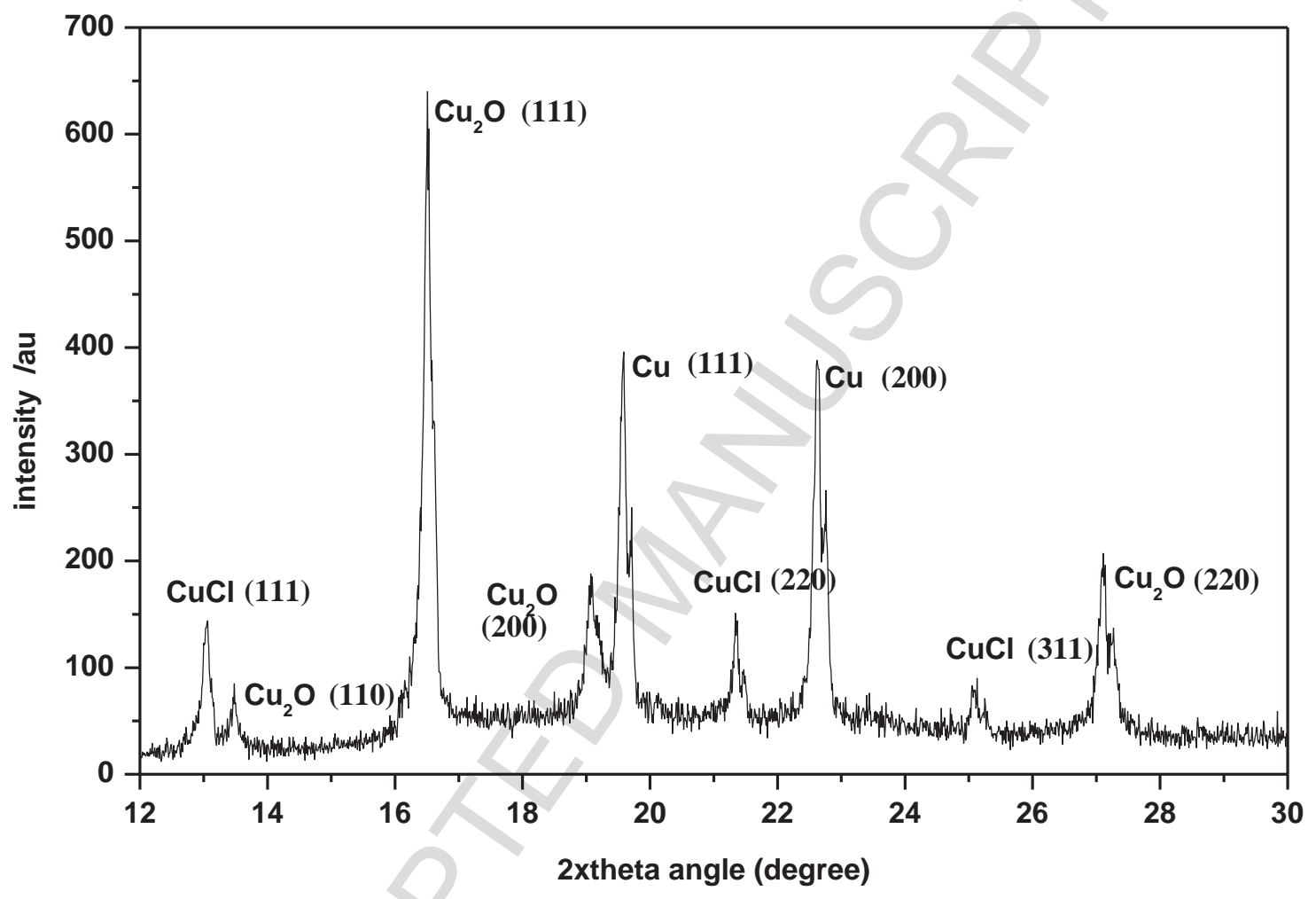

Fig. 4 

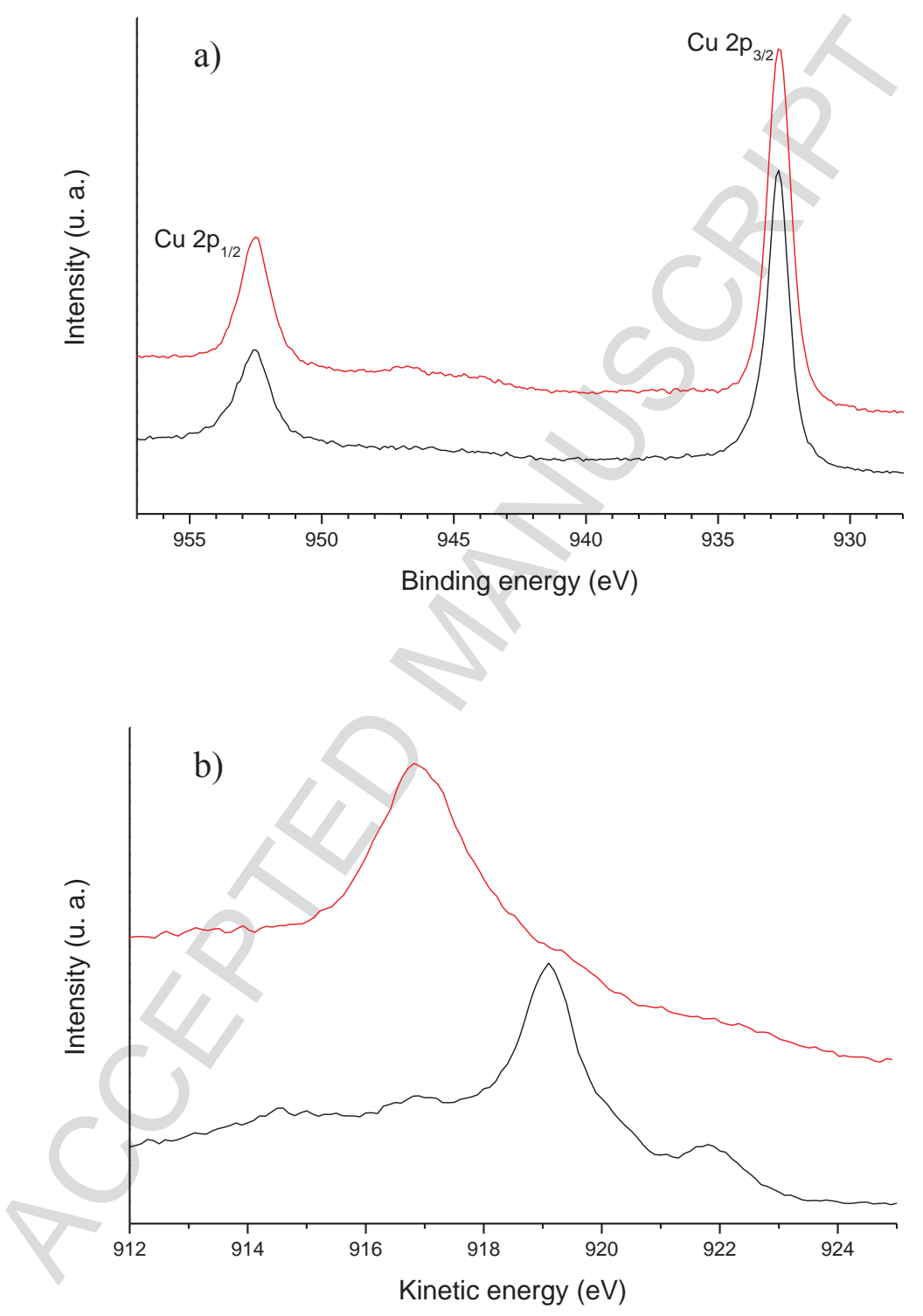

Fig. 5 

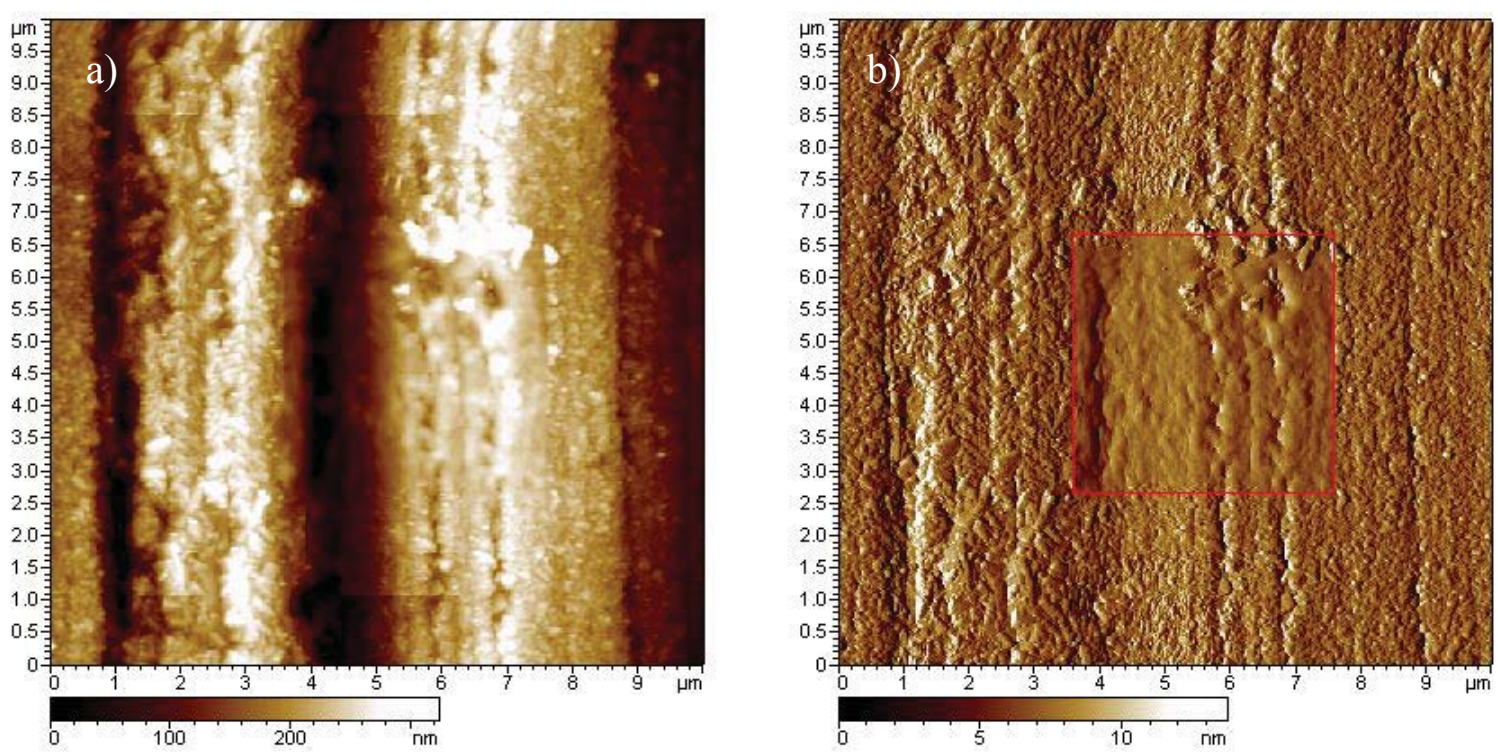

Fig. 6 

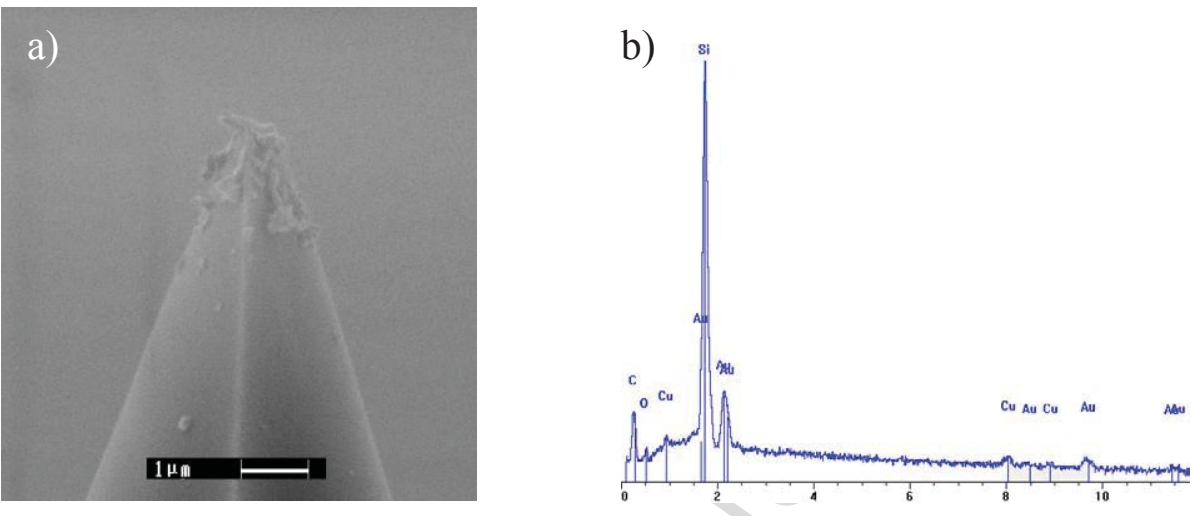

Fig. 7 

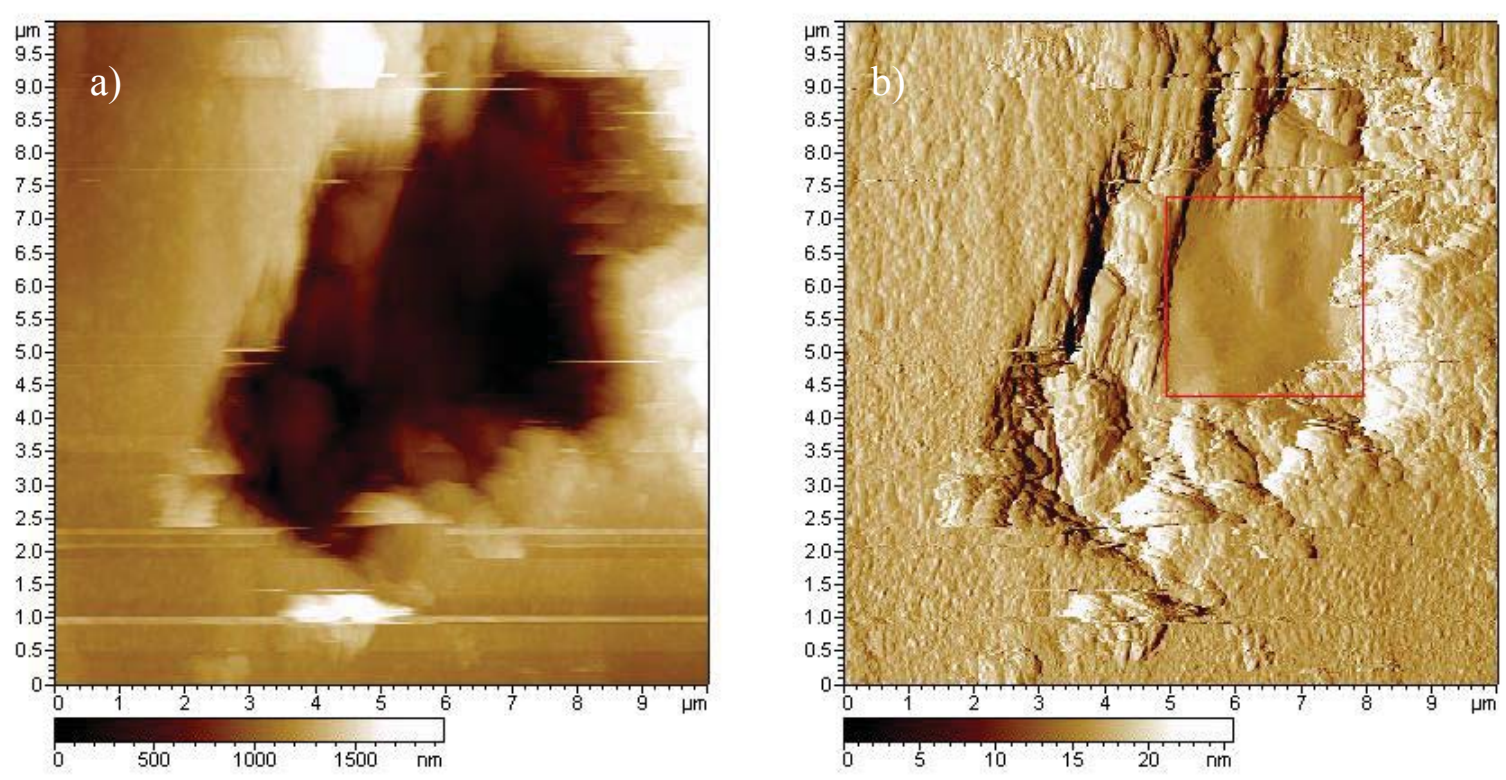

Fig. 8 